\title{
LETTER
}

\section{Non-invasive determination of respiratory system mechanics in pressure support ventilation using the expiratory time constant?}

\author{
Tobias Becher*, Dirk Schädler, Inéz Frerichs and Norbert Weiler \\ See related research by Al-Rawas et al., http://ccforum.com/content/17/1/R23
}

In the previous issue of Critical Care, we read with interest the article by Al-Rawas and colleagues [1], who proposed a method for the determination of respiratory system mechanics (RSM) in different ventilatory modes. We have some concerns regarding the applicability of the described method during pressure support ventilation (PSV).

In particular, all equations proposed in the article contain a term called 'inhaled flow rate'. Since there is no constant inspiratory flow during PSV, it is unclear how the authors determined its exact value. Furthermore, all of these equations are transformations of the equation of motion of the respiratory system and require the knowledge of the inspiratory driving pressure, for which the authors apparently used the inspiratory airway pressure. However, in PSV, the patients' spontaneous breathing activity contributes to inspiratory driving pressure to a variable degree [2]. It would be interesting to know how the authors took the patients' muscular effort $\left(\mathrm{P}_{\text {mus }}\right)$ into account. Finally, we would like to know why the numbers of patients in the PSV and in the volume-controlled continuous mandatory ventilation groups differ from the numbers of measurements plotted in the corresponding figures. For example, 23 patients were in the PSV group (according to Table 1), but 25 measurements are shown in Figure 4a,b and only 14 are shown in Figure 4c.

A non-invasive determination of RSM during PSV is certainly helpful in a clinical setting, and we would appreciate if the authors provided a detailed description of how they handled the non-constant qualities of flow and $\mathrm{P}_{\text {mus }}$ during PSV.

\section{Authors' response}

Nawar Al-Rawas, Michael J Banner, Neil R Euliano, A Daniel Martin, Carl Tams and Andrea Gabrielli

We thank the editor for the opportunity to reply to the letter by Becher and colleagues, which concerns our expiratory time constant method for calculating plateau pressure $\left(\mathrm{P}_{\mathrm{plt}}\right)$, respiratory system compliance $\left(\mathrm{C}_{\mathrm{rs}}\right)$, and total resistance $\left(R_{\text {tot }}\right)$ [1] when patient inspiratory effort is present during PSV. In regard to our equations, any single point from inhalation - not just peak inspiratory flow rate or tidal volume, but any simultaneous flow, volume, or pressure value - can be used to calculate $\mathrm{P}_{\mathrm{plt}}, \mathrm{C}_{\mathrm{rs}}$, and $R_{\text {tot }}$. We sought to find a point very near the end of inhalation at which patient inspiratory effort is minimal. Using flow, volume, and pressure near end-inhalation

*Correspondence: tobias.becher@uksh.de

Department of Anesthesiology and Intensive Care Medicine, University Medical Center Schleswig-Holstein, Campus Kiel, Schwanenweg 21, 24103 Kiel, Germany minimizes confounding effects of patient inspiratory effort on the equations and provides accurate estimates of $\mathrm{P}_{\mathrm{plt}}, \mathrm{C}_{\mathrm{rs}}$, and $\mathrm{R}_{\mathrm{tot}}$.

As for the number of PSV patients, there was a typo in Table 1 ; it should have stated that $\mathrm{n}=25$, not $\mathrm{n}=23$. We apologize for the error. This error does not affect the results as shown on the PSV regression plots in Figure 7; these plots are all correct.

\section{Abbreviations}

$C_{\text {s, }}$ respiratory system compliance; $\mathrm{P}_{\text {ms }}$, pressure developed by the patient's respiratory muscles; $P_{\text {ptt' }}$ plateau pressure; $P S V$, pressure support ventilation; $R S M$, respiratory system mechanics; $R_{\text {tor }^{\prime}}$ total resistance.

\section{Competing interests}

TB, DS and NW received lecture fees from Dräger Medical (Lübeck, Germany) and cooperated with Dräger Medical in a research project for closed-loop control of mechanical ventilation. DS received consulting fees from Dräger Medical. IF declares that she has no competing interests. MJB is a consultant for Convergent Engineering (Newberry, FL, USA), which is a developer of software used in the related research. NRE is president of and holds stock in 
Convergent Engineering. CT is an associate of Convergent Engineering. The authors of the related research received clinical research funds from PhilipsRespironics Inc. (Hartford, CT, USA), the study sponsor, and have applied for a patent.

\section{Published: 3 April 2013}

\section{References}

1. Al-Rawas N, Banner MJ, Euliano NR, Tams CG, Brown J, Martin AD, Gabrielli A: Expiratory time constant for determinations of plateau pressure, respiratory system compliance, and total resistance. Crit Care 2013, 17:R23.
2. Iotti GA, Braschi A, Brunner JX, Palo A, Olivei MC: Noninvasive evaluation of instantaneous total mechanical activity of the respiratory muscles during pressure support ventilation. Chest 1995, 108:208-215.

doi:10.1186/cc12562

Cite this article as: Becher T, et al:: Non-invasive determination of respiratory system mechanics in pressure support ventilation using the expiratory time constant? Critical Care 2013, 17:424. 